\title{
Orthodontic repositioning of a malposed and dilacerated central incisor
}

\section{Hegde $C^{1}$, Hegde $M^{1}$, Parajuli $U^{2}$}

${ }^{1}$ Reader, ${ }^{1}$ Associate Professor, Department of Orthodontics and Dentofacial Orthopedics, KD Dental College and Hospital, Mathura, India, ${ }^{2}$ Dental Surgeon, Department of Dentistry, Manipal College of Medical Sciences, Pokhara, Nepal

\begin{abstract}
Dilacerated teeth are commonly seen in the maxillary anterior region. They are a cause for concern to both patients as well as parents when such teeth do not erupt or erupt in an unusual position. Careful planning is required while aligning such teeth. Orthodontists often hesitate aligning severely dilacerated teeth due to high chances of failure. A case of a dilacerated and malposed right central incisor in an eleven-year-old male patient is presented here. The tooth was orthodontically repositioned despite its unusual position and severely dilacerated root.
\end{abstract}

Key words: Dilacerated teeth, Malposed teeth, Dilacerated central incisor.

$\mathrm{D}$ ilacerated roots are a common finding in the maxillary central incisor region especially in the permanent dentition ${ }^{1,2}$. However their alignment poses a clinical challenge to the orthodontists especially when they are severely dilacerated, and malposed or impacted. Treatment depends upon the early diagnosis ${ }^{3}$, degree of dilaceration, position of the tooth and patients motivation ${ }^{4}$. A case of severely malposed and dilacerated permanent right central incisor in an eleven-year-old male patient has been presented. Though the position of the tooth did not favour good prognosis, Orthodontic treatment was tried to bring the tooth into alignment and it yielded satisfactory result.

\section{Case report}

An eleven- year- old male patient in late mixed dentition stage presented to the Out Patient Department complaining of laceration and pain in the upper lip. Intra oral examination revealed a malposed right upper central incisor, which was placed high in the labial vestibule. The tooth was severely malposed with the crown rotated more than $90^{\circ}$ from normal. The palatal surface was facing labially and the root development was in the palatal plane. (Fig1 and Fig 2). The tooth was lacerating the upper lip due to its unusual position. There was no history of trauma but, an over retained root probably of the deciduous incisor and another impacted supernumerary tooth were present between the malposed right central incisor and the left central incisor (Fig 3). Both the supernumerary tooth and the over retained deciduous root stump were extracted during the orthodontic treatment (Fig 4).

Considering the unfavourable position of the tooth, the patient and the guardian were both informed that the prognosis was not very good and that if orthodontic treatment failed then the next option would be extraction and artificial replacement of the tooth. Strap up of the upper arch was done using Begg appliance and a bracket was bonded onto the palatal surface, as it was the only surface seen in the oral cavity. The malposed and dilacerated right central incisor was tied to the main arch wire. Light forces using elastic chain were used to bring the tooth into alignment.

When the labial surface of the tooth could be visualized, the bracket was rebounded to the labial surface and continuous arch mechanics was used to finish the case. (Fig 5) This was followed by debonding and retentive phase of six months using Hawley's removable retainer (Fig 6, Fig 7and Fig 8).

Correspondence

Dr. Chatura Hegde

Department of orthodontics and dentofacial orthopedics

K. D. Dental College and hospital. Chhatikara, Mathura 281001

E-mail: chaturahegde@yahoo.co.uk 
Fig 1 and Fig 2: Intra Oral Pre Treatment

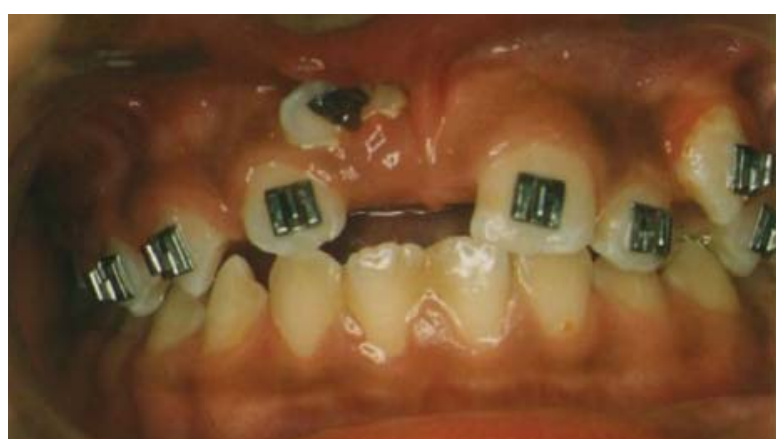

Fig 1: Showing the right maxillary central incisor malposed in the labial vestibule with a bracket bonded on the palatal surface.

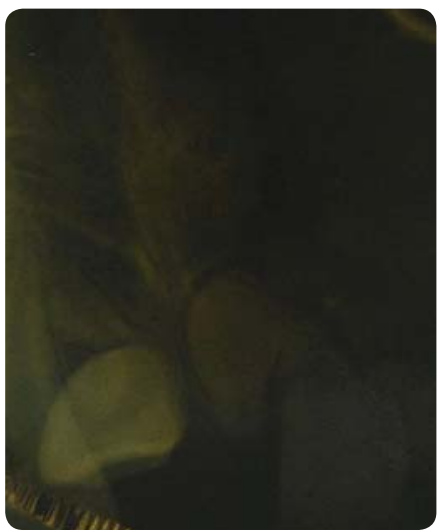

Fig 3: Pre Treatment Radiograph

Showing the malposed and dilacerated right central incisor, the normal left central incisor, an impacted supernumerary tooth and the residual root piece of deciduous incisor

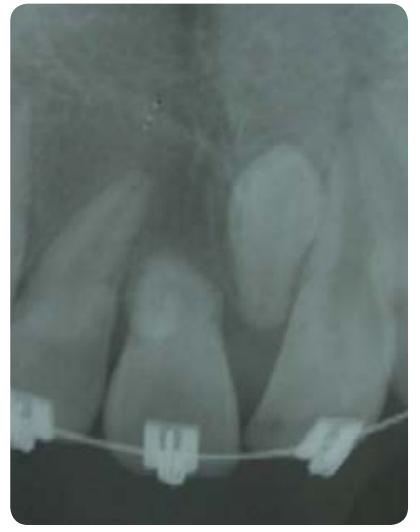

Fig 4: During Treatment Intra Oral Radiograph

Showing considerable alignment of the dilacerated tooth. The supernumerary tooth was extracted thereafter.

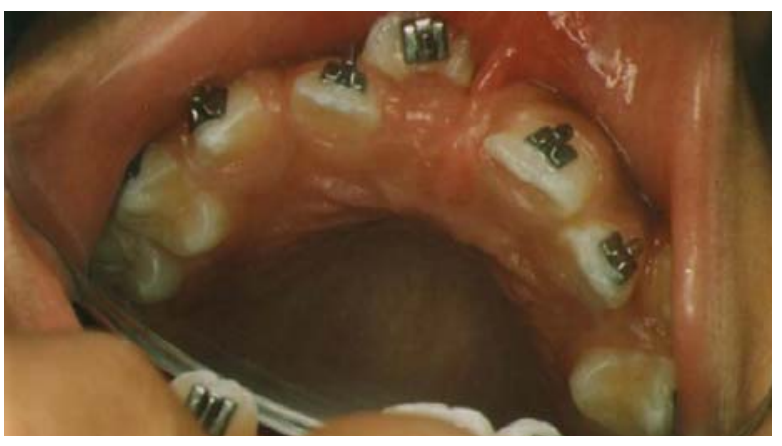

Fig 2: Showing the occlusal view of the maxillary arch with the incisor lacerating the upper lip.

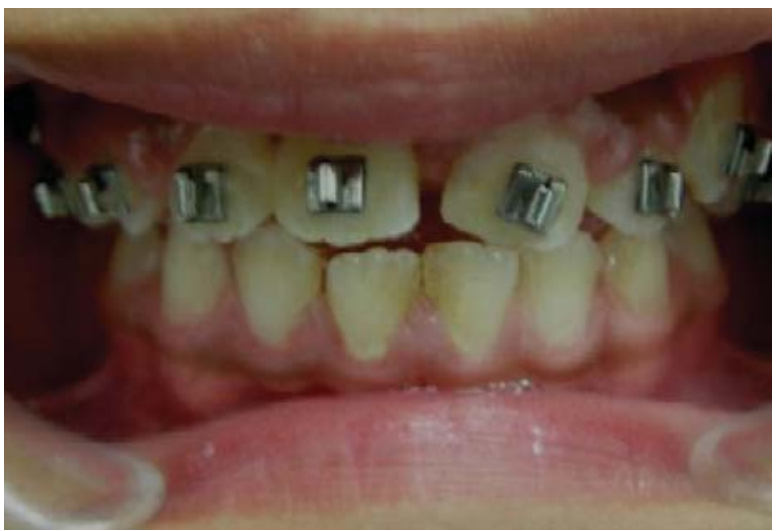

\section{Fig 5: During Treatment Intra Oral}

When the labial surface could be seen the palatal bracket was bonded labially to continue further alignment.
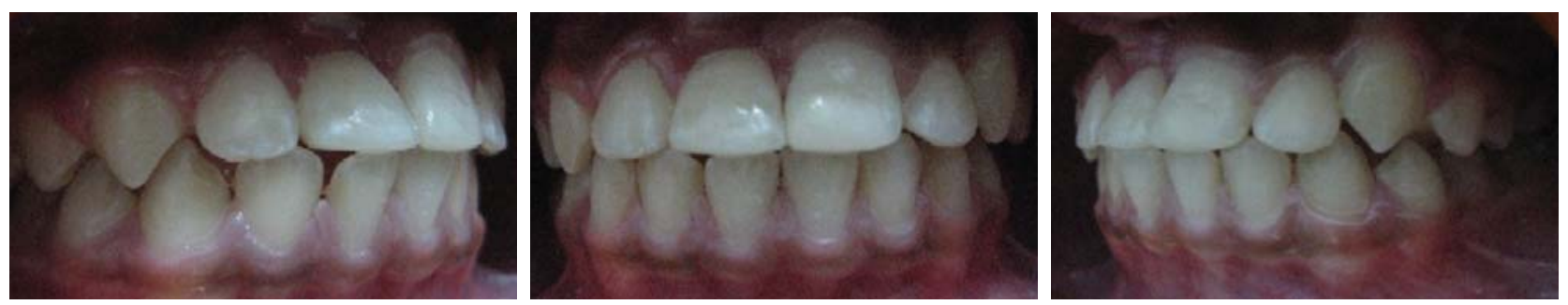

Fig 6, 7, \& 8: Post Treatment Intra Oral

Showing favorable alignment and acceptable gingival margin of the malposed and dilacerated right central incisor. 


\section{Discussion}

Dilaceration is a deformity that results from a disturbance in relationship between uncalcified and already calcified portions of a developing tooth ${ }^{5}$. Trauma has been suggested as the main etiological factor ${ }^{6,7}$ but in this case neither the patient nor guardian gave any history of trauma. When dilacerated teeth are examined microscopically they appear flawless further reducing the likelihood of trauma being the sole etiological factor $^{3}$. Dilacerated teeth have been observed with teeth with no predecessors suggesting that they may be due to the ectopic development of the tooth germ $^{8,9}$. Orthodontic treatment of dilacerated incisors poses a clinical challenge. Few cases of successful treatment of severely dilacerated incisors have been reported to date $^{10,11}$.

Ted Mc Namara et $\mathrm{al}^{3}$ have suggested that successful outcome of such dilacerated incisors is enhanced when treatment is started early so that the epithelial root sheath can be redirected and the root develops in the correct spatial relation of the aligned crown. Surgical extraction of a dilacerated incisor is a common practice but commits the patient to extensive future restorative care. According to Uematsu et al $^{12}$ even if extraction and subsequent restoration of such teeth is planned the orthodontic traction of that tooth should be performed initially to improve esthetics and to maintain proper bone height.

\section{References}

1. Kilpatrick NM, Hardman PJ, Welbury RR. Dilaceration of a primary tooth. In J Paed dent. 1991; 1:151-3.
2. Chadwick SM, Millet D. Dilaceration of a permanent mandibular incisor: A case report. Br J Orthod. 1995; 22:279-81.

3. Mc Namara T, Woolfe SN, McNamara CM. Orthodontic management of a dilacerated maxillary central incisor with an unusual sequela: A case report. J clinical Orthod. 2003; 35:293-7.

4. Howard RD. Letter to the editor. Br Dent. J. 1984; 156: 160 .

5. British Standards Institute. Glossary for Dental Terms. UK: British Standards Institute; 1982.

6. Ravn JJ. Sequelae of acute mechanical traumata in primary dentition: A clinical study. J Dent Child. 1968; 35: 281-9.

7. Howard RD. The congenitally displaced maxillary incisor: A differential diagnosis. Dent Pract. 1970; 20: 361-70.

8. Stewart DJ. Dilacerated unerupted maxillary central incisors. Br Dent J. 1978; 145: 229-33.

9. Andreasen JO, Ravn JJ. Epidemiology of traumatic dental injuries to primary and permanent teeth in a Danish population sample. Int J oral Surg. 1972; 1:235-9.

10. Kolokithas G, Karakasis D. Orthodontic movement of dilacerated maxillary central incisor. Am J Orthod. 1979; 76:310-5.

11. Stewart DJ. Dilacerated unerupted maxillary central incisors. Br Dent J. 1978; 145:229-33.

12. Uematsu S, Uematsu T, Furusawa K, Deguchi $\mathrm{T}$, Kurihara S. Orthodontic treatment of an impacted maxillary central incisor combined with surgical exposure and apicoectomy. Angle Orthod. 20004; 74: 132-6. 